Journal of Applied Veterinary Sciences, 6 (4): 58 - 66 (October, 2021).

ISSN: Online: 2090-3308, Print: 1687-4072

Journal homepage : https://javs.journals.ekb.eg

\title{
Effects of Melatonin on Behavioural Activities in Acetaminophen-Induced
} Autism in Rat

\author{
Ghada, A. Taqa ${ }^{1 *}$; Hiba, A. Al-Sheikh ${ }^{2}$; and Luma, I. Al-Allaf ${ }^{3}$ \\ ${ }^{1}$ Department of Dental Basic Science, College of Dentistry, University of Mosul, Mosul, Iraq. \\ ${ }^{2}$ Ministry Of Health, Nineveh Health Directorate, Mosul, Iraq. \\ ${ }^{3}$ Department of Anatomy, College on Medicine, University of Mosul, Mosul, Iraq. \\ *Corresponding Author, Ghada A. Taqa, E-Mail: ghadataqa@ uomosul.edu.iq
}

\begin{abstract}
The present study aims to investigate the effect of acetaminophen in male rats after early postnatal exposure to acetaminophen on several behavioural alterations and its role to precipitate autistic-like behaviour with investigating the ameliorating role of melatonin on these parameters. Thirty healthy Albino male rat pups were used in this study. On a postnatal day 3 (PND3), the rat pups were divided into three groups (10 pups per group). Group1: As a control group, pups injected with normal saline for 7 days subcutaneously then administered with normal saline for 2 weeks orally. Group 2: pups injected acetaminophen subcutaneously in a dose $(50 \mathrm{mg} / \mathrm{kg})$ once daily for 7 days, then these pups were administrated with normal saline for 2 weeks. Group 3: includes pups that were injected acetaminophen subcutaneously in a dose $(50 \mathrm{mg} / \mathrm{kg})$ once daily for 7 days then administrated with melatonin (10 $\mathrm{mg} / \mathrm{kg}$ ) for 2 weeks. Behavioural tests, such as nest seeking, were performed at PND 9; negative geotaxis test was done at "PND 15 and 17", an open field test was done at PND21. The present study demonstrated that acetaminophen exposed rat pups exhibited a significant difference in behavioural tests: nest seeking test showed that the pups of group 2 to approach the maternal bedding was $(10.00 \pm 1.51) \mathrm{sec}$ which was significantly higher than the time of the control group $(4.50 \pm 2.19) \mathrm{sec}$. At PND15, the negative geotaxis test showed a significant increase in time spend to rotate $180^{\circ}$ of the pups of group $2(7.30 \pm 2.86) \mathrm{sec}$ when compared with that of the control group $(3.50 \pm 0.63) \mathrm{sec}$ and melatonin treated group $(4.56 \pm 0.63) \mathrm{sec}$. While at PND17, pups showed a significant increase in time spend to rotate $180^{\circ}$ in negative geotaxis test in group $2(7.40 \pm 2.90)$ sec compared with that of the control group $(3.12 \pm 1.33) \mathrm{sec}$, and that of the melatonin treated group (4.18 $\pm 1.43) \mathrm{sec}$. Data of open field test showed that pups of group 2 were traveled significantly more total distance (number of squares crossed) $(31 \pm 8.34)$

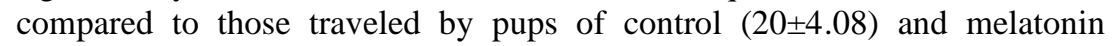
treated groups (22 \pm 7.43 ). Administration of acetaminophen at dose $50 \mathrm{mg} / \mathrm{kg}$ from PND 3 to PND10 induces autistic-like behavioural manifested by several alterations in rat pups. These alterations were ameliorated by melatonin administration (10 $\mathrm{mg} / \mathrm{kg}$ for 2 weeks) after exposure to acetaminophen.
\end{abstract}

Original Article:

DOI:https://dx.doi.org/10.21608/javs .2021 .89536 .1098

Received :06 August, 2021.

Accepted :09 September, 2021.

Published in October, 2021.

This is an open access article under the term the Creative Commons Attribution 4.0 (C BY) International License . To view a copy this license, visit:

http://creativecommons.org/licenses/by/4.0/

Keywords: Acetaminophen, Autistic-like behaviour, Melatonin, J. Appl. Vet. Sci., 6(4): $58-66$. Negative geotaxis, Open field test.

\section{INTRODUCTION}

Autism is defined as a certain set of behaviours and is a "spectrum condition" that affects people differently and to varying degrees. While there is currently no known single cause of autism, early diagnosis helps a person receive the support and services they need, leading to a quality life filled with opportunity (Pelsöczi, et al., 2020). Some of the suspected risk factors for autism include: having an immediate family member with autism, genetic mutations, being born to older parents, low birth weight, metabolic disorder, exposure to heavy metals and environmental toxins, a history of viral infections, 
and fetal exposure to the medications such as valproic acid, thalidomide or acetaminophen (Baker and Shaw, 2021).

An acetaminophen usage in newborns and young children may be considerably more strongly related to autism than its use during pregnancy. Thus, increasing acetaminophen exposure, exacerbated by inflammation and oxidative stress, is one explanation for the increased prevalence of autism (Parker, et al., 2017). Cellular stress and cytotoxicity can be produced by oxidative stress, caused by a redox state imbalance. Increased oxidative stress has been linked to various neurological diseases (Bjørklund, et al., 2020).

The use of natural products and antioxidants substances, such as melatonin, in the treatment of autistic behaviours has attracted a great deal of attention (Bittker, 2016). Melatonin is a neurohormone produced mostly by the pinealocytes in the pineal gland and is widely known for its role in controlling the circadian sleep-wake rhythm. It is formed from tryptophan, which is hydroxylated and subsequently decarboxylated to make 5-hydroxytryptamine or serotonin. Melatonin is of interest in autism spectrum disorder (ASD) because of its role in neurodevelopment abnormalities. Melatonin physiology may be involved or closely associated with the pathophysiology and behavioural expression of autistic disorder and reports of sleep-wake rhythm problems in people with autism (Lalanne, et al., 2021).

Melatonin has been demonstrated to affect basal metabolism, oxidative stress, inflammation, apoptosis, and prevent premature aging and cancer at a practical level. This strengthens interest in the research of melatonin in developmental disorders (Kubatka, $\boldsymbol{e t}$ al., 2018).

Case-control research found that taking acetaminophen early in life is linked to an elevated risk of ASD. When all children were evaluated, the investigators found that children who used acetaminophen at the age of 12 to 18 months were eight times more likely to develop ASD than those who did not. However, current research is insufficient to explain how acetaminophen causes alterations in the brain during development that led to developmental disorders (Rigobello, et al., 2021).

The present study aims to investigate the effect of melatonin on autistic-like behavior induction by acetaminophen and study the ameliorating effect of melatonin on behavioural alterations induced by acetaminophen.

\section{MATERIIALS AND METHODS}

\section{Modeling Experiment:}

Ten pregnant Albino rats were obtained from Animal House at the College of Veterinary Medicine, University of Mosul, Iraq. The animals were kept in plastic rodent cages $(28 \times 22 \times 18) \mathrm{cm}$ with wire mesh covers.

Homogenized wood shavings were employed as bedding at ambient temperature $\left(22^{\circ} \mathrm{C} \pm 2^{\circ} \mathrm{C}\right)$ and humidity $(55 \% \pm 5 \%)$. Food and water ad libitum were supplied in standard light condition (12-hour light/12hour dark cycle) (Sztainberg and Zoghbi, 2016; Dawood et al., 2020). Pregnant rats were checked every morning by a veterinarian for their general health and delivery of animals. When the newborn pups were seen, that day was considered as PND 0 (Fig. 1). At PND0, male rat pups were selected for experimental study and not the females to avoid hormonal effects in females (Jeon et al., 2018). All investigations were carried out in conformity with the institutional animal research ethics committee's requirements.

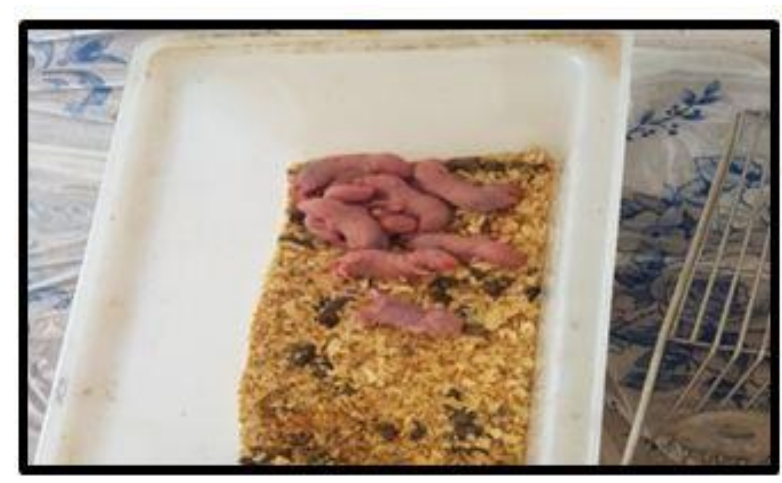

Fig. 1: A photograph of pups that were used in this work.

\section{Medications:}

Acetaminophen ampoules (London medical, UK). Each ampoule contains $120 \mathrm{mg} / \mathrm{ml}$ of acetaminophen. Melatonin tablets (Win pharmaceuticals, Canada). Each tablet contains $5 \mathrm{mg}$ of melatonin.

\section{Experimental Groups and Procedures:}

At PND 0, male rat pups were divided randomly into three (3) experimental groups and housed as ten animals per group (Philippot, et al., 2017) as following:

The Control group $(n=10)$ includes pups injected subcutaneously with normal saline in the dorsal neck region once daily from PND3 to PND10. They received normal saline orally for 2 weeks to encounter the same conditions as other groups.

The Acetaminophen group $(n=10)$ includes pups injected subcutaneously with a similar approach with 


\section{Effects of Melatonin on Behavioural Activities in......}

$(50 \mathrm{mg} / \mathrm{kg})$ of acetaminophen once daily from PND3 to PND10 to precipitate autistic-like behavior. Then they received with normal saline orally for 2 weeks to encounter the same conditions of other groups (Philippot, et al., 2017).

The melatonin-treated group $(n=10)$ includes pups who were injected subcutaneously with a similar approach with $(50 \mathrm{mg} / \mathrm{kg})$ of acetaminophen once daily from PND3 to PND10 to precipitate autistic like behaviour (Philippot $\boldsymbol{e t}$ al., 2017). They were treated with melatonin $(10 \mathrm{mg} / \mathrm{kg})$ orally for 2 weeks from PND11 to PND25 (El-Ansary, et al., 2016).

The dose of acetaminophen injected to pups depend on this equation (Nair and Jacob, 2016) :

Animal dose $(\mathrm{mg} / \mathrm{kg})=$ Infant dose $(\mathrm{mg} / \mathrm{kg}) \times$ Infant $(\mathrm{Km}) /$ Animal $(\mathrm{Km})$.

The correction factor $(\mathrm{Km})$ is a stable value equal to 20 in infants and 6.0 in rats. The acetaminophen dose of the infant was chosen as applied in the clinical treatment protocols $(15 \mathrm{mg} / \mathrm{kg})$ (Temple, et al., 2017; Asymida, et al., 2020). The gavage needle was properly attached to the insulin syringe. It was introduced out of the side of the mouth with the observation of the mouth roof (Figs. 2A,B). Then melatonin was administered into the esophagus toward the stomach once the needle passed to the right length (Al-Allaf and Al-Ashoo, 2021).

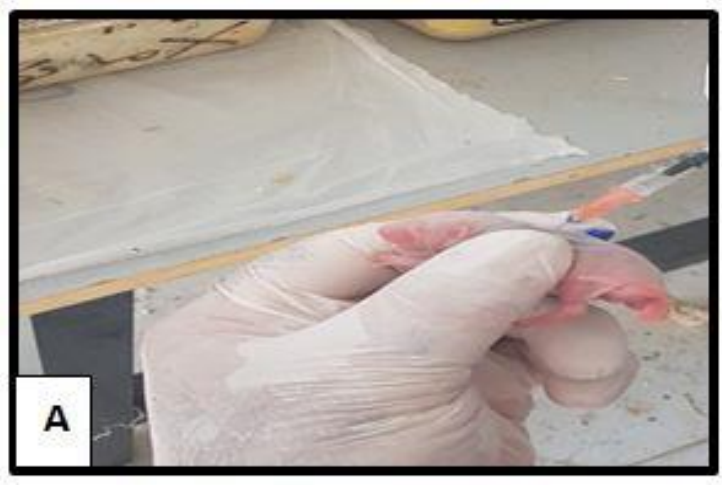

Fig. 2A: A photograph showed the procedure of acetaminophen administration.

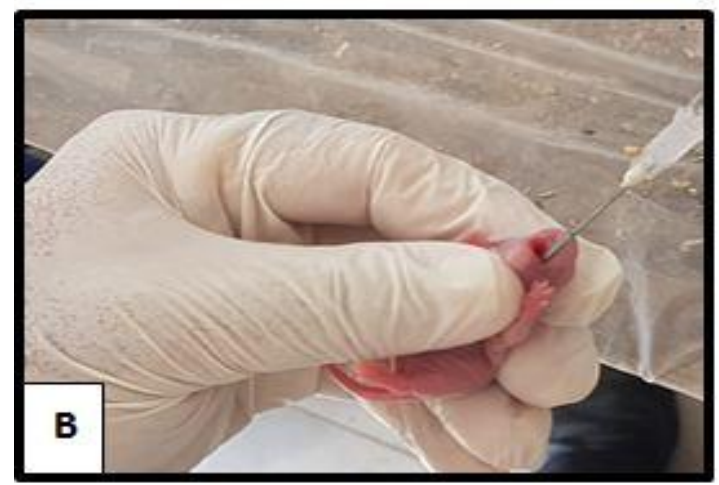

Fig. 2B: A photograph showed the procedure of melatonin administration.

\section{Behavioral Tests:}

Thirty male pups were used in our behavioural studies. Behavioural tests were performed during the daytime. Before the behavioural studies, animals were habituated to the place of the experiment for a minimum of one hour before the start of the behaviour tests, as follows:

\section{Nest-Seeking Response:}

On PND9, the latency to approach maternal bedding was assessed ( $n=10 /$ group). Bedding from the maternal home cage and clean bedding were placed on paper at either corner of the testing cage $(31.7 \times 17.2 \times 14.2 \mathrm{~cm})$ (Figs. 3A,B), and the observer recorded the latency to approach bedding using a mobile camera in the most time of observation is $60 \mathrm{sec}$ (Barrett, et al., 2017).

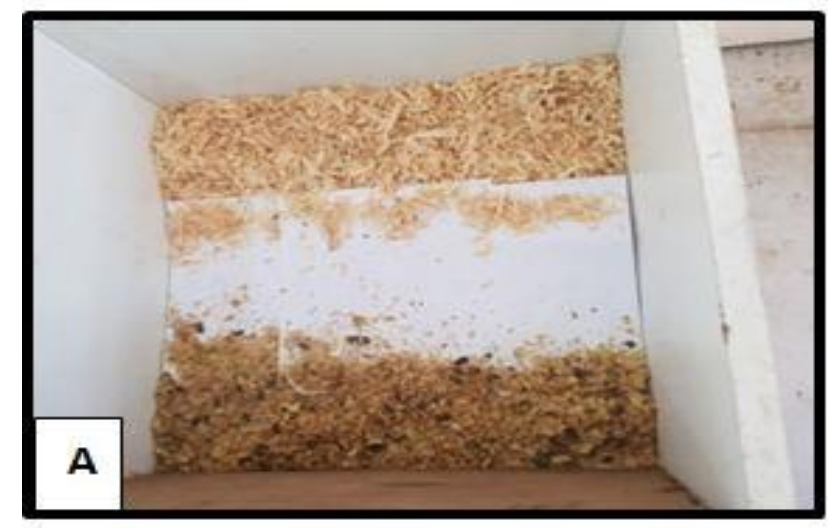

Fig. 3A: A photograph showed nest seeking test.

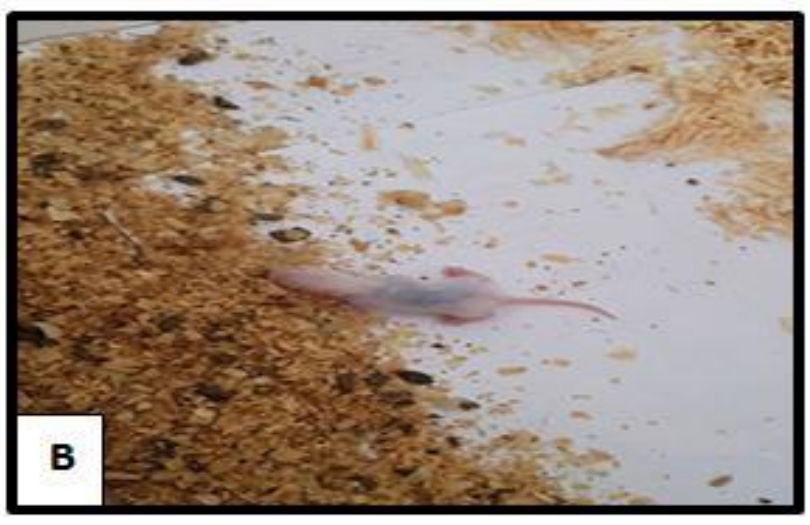

Fig. 3B: A photograph showed the pup during test.

\section{Test for Negative Geotaxis (NG):}

The negative geotaxis test is an automatic vestibular response test used in rodents to detect the geogravitational stimuli and assess the sensorimotor ability (Figs. 4A,B). During this test, a wood platform $(12.5 \times 40 \mathrm{~cm} \mathrm{w} \times \mathrm{h})$ was used and is covered with rough paper. Pups of all groups were tested in this test at different PNDs (15 and 17). In this test, rat pups were maintained on a $45^{\circ}$ inclined plane. The mean time to rotate to $180^{\circ}$ was documented using a mobile camera (Ruhela, et al., 2019). 


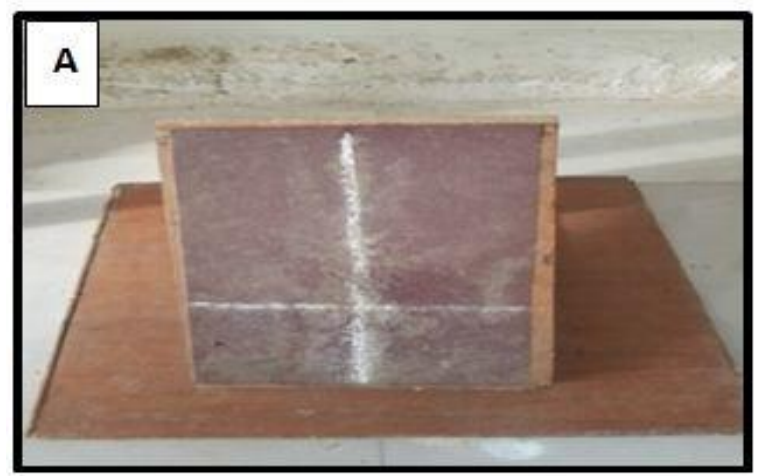

Fig. 4A: A photograph showed negative geotaxis equipment.

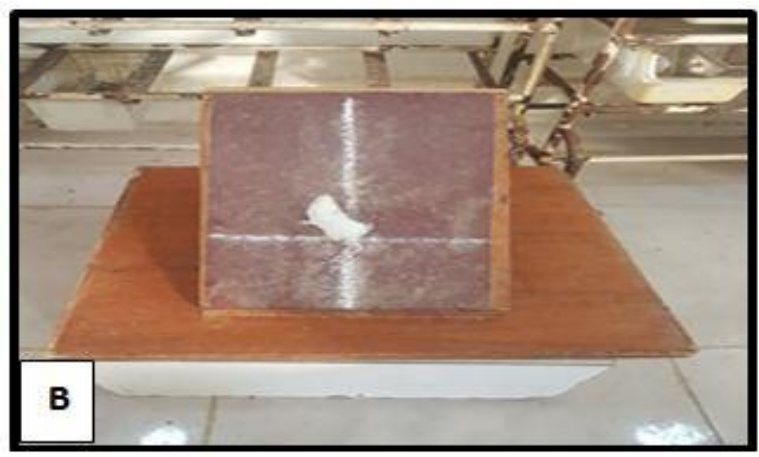

Fig. 4B: A photograph showed a pup during the NG test.

\section{The Open Field Locomotors Test:}

Rats of all three groups underwent open field testing at PND 21. This test is performed to assess the degree of anxiety and locomotors activity in rodents (Taqa, 2013). The open-field test arena is a square box $(50 \times 50 \mathrm{~cm})$ divided into 25 squares of identical size $(10 \times 10 \mathrm{~cm})$. The box is virtually demarcated into a central zone and peripheral zones (Fig. 5).

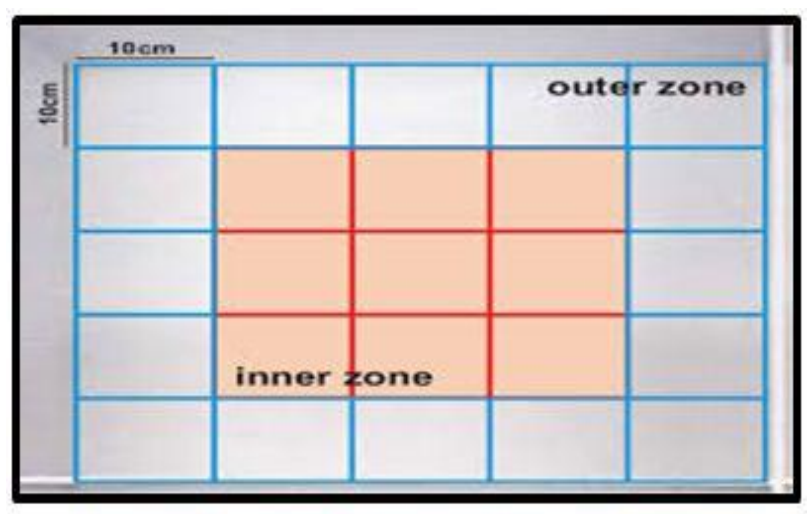

Fig.5: A photograph showed open field locomotors test.

The experimental pup was placed into the center area of the arena and allowed to explore the arena for three minutes. The video camera of the mobile measured the activity of a tested pup in the box.
The total distance that moved (total bar crossing in units) in the whole arena (outer+inner) and the total distance moved in the inner zone (centrally of bar crossing in units) were measured. The overall distance that each pup moved is considered an indicator for locomotors activity, while total distance moved in the inner zone is considered an indicator for anxiety level (Mony, et al., 2016; Wang, et al., 2020).

\section{Statistical Analysis:}

Statistical Package Social Statistics (SPSS) version 19 was used for statistical analysis. The data were expressed as mean $\pm \mathrm{SD}$. A one-way analysis of variance (ANOVA) with a post-hoc Duncan's test was used to examine the differences between groups. An independent sample t-test was used to examine the differences between groups in this test. Statistical analysis comparisons were considered significant at $(p$ $\leq$ 0.05)(Ali and Bhaskar, 2016).

\section{RESULTS}

\section{Nest-Seeking Response Results:}

At PND 9 statistical analysis by independent sample t-test at $\mathrm{p} \leq 0.05$, the time of pups of acetaminophen group to approach maternal was $(10.00 \pm 1.51) \mathrm{sec}$, which was significantly higher than

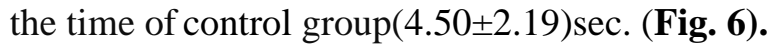

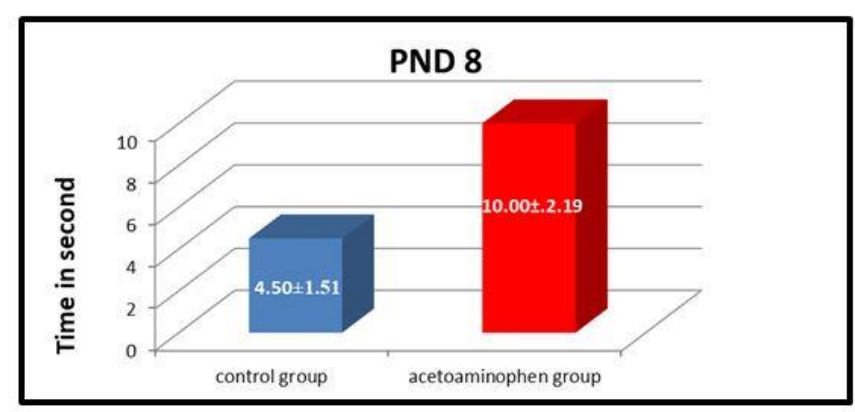

Fig.6: A histogram of the nest-seeking response data of all pups at PND9.

\section{Negative Geotaxis Measurements (NG):}

Negative geotaxis measurements were taken in the different time courses (PNDs 15and17) during this work. At PND15, the ANOVA test revealed a significant difference at ( $\mathrm{p}$ 0.05) in time to rotate $180^{\circ}$ in NG test of the pups of acetaminophen group (7.30 \pm 2.86$)$ sec when compared with that the control group (3.50 \pm 0.63$) \mathrm{sec}$ and melatonin group $(4.56 \pm 0.63) \mathrm{sec}$, while no significant difference in time to rotate $180^{\circ}$ in NG test between pups of both control and melatonin treated groups.

Finally, in the NG test, there is a decrease in the time taken to rotate $180^{\circ}$ for pups of control and melatonin-treated groups at PND17. At PND17, the ANOVA test revealed a significant difference at $(p$ 
$0.05)$ in time to rotate $180^{\circ}$ in NG test of pups of the acetaminophen group (7.40 \pm 2.90$) \mathrm{sec}$ when compared with that of the control group $(3.12 \pm 1.33) \mathrm{sec}$, and that of the melatonin treated group $(4.18 \pm 1.43) \mathrm{sec}$, while no significant difference in time to rotate $180^{\circ}$ in NG test between pups of the control group and melatonin groups. On the contrary, the time taken to rotate $180^{\circ}$ was increased in pups exposed to acetaminophen alone at PND17 (Fig. 7).

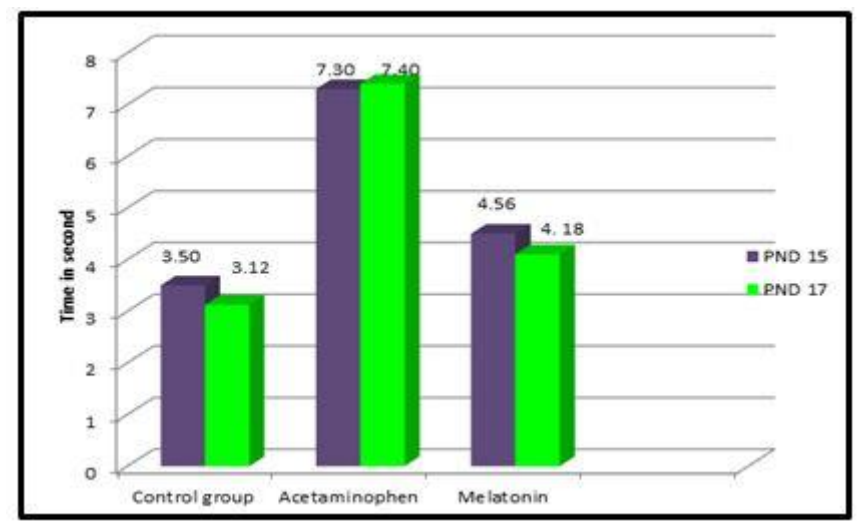

Fig. 7: Negative geotaxis data on PND 15 and 17.

\section{Open Field Measurements :}

The result of the open-field test showed that the pups of the acetaminophen group traveled significantly more total distance (number of squares crossed) $(31 \pm 8.34)$ compared to those traveled by pups of control (20 \pm 4.08$)$ and melatonin treated groups $(22 \pm 7.43)$. However, there is no significant difference between the traveled total distance by control and melatonin-treated groups. On the other hand, in the central zone, pups of the control $(9.25 \pm 1.25)$ and melatonin treated groups $(8.25 \pm 1.41)$ traveled a far greater distance significantly (number of squares crossed centrally) than those of the acetaminophen group (5.00 \pm 0.81$)$. However, pups of both control and melatonin-treated groups traveled similar distances. These results demonstrate that the acetaminophen groups' locomotor activity and anxiety levels are significantly higher than control and melatonin groups (Fig. 8).

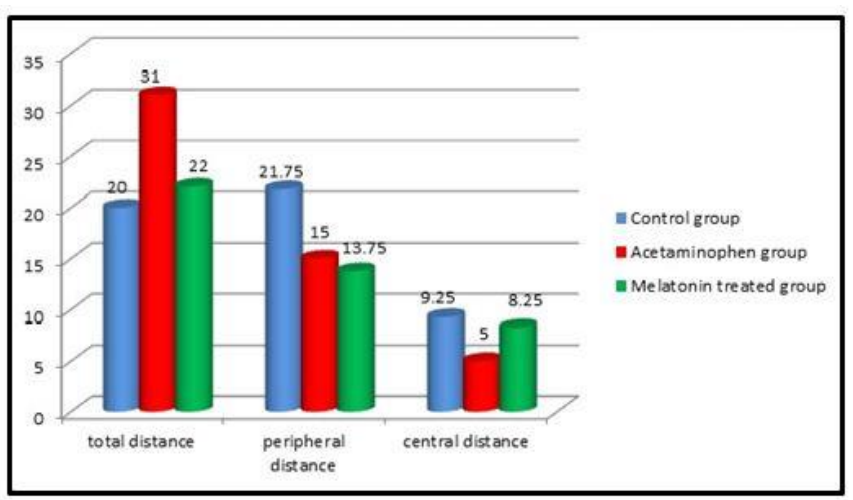

Fig. 8: A histogram of squares crossed in open field test by pups in all study groups.

\section{DISCUSSION}

Rats are by far the most used animals in neurodevelopmental disorder studies, especially when assessing behavioral endpoints (Ellenbroek and Youn, 2016). Animal experimentation has been one of the building blocks of biological and biomedical research, particularly in the fields of clinical medicine, pharmacology, neurodevelopmental, and toxicology (Pires, et al., 2016 and Al-Jureisy et al., 2020).

The acetaminophen model is a well-validated model of ASD (Parker, et al., 2017). Viberg et al., (2014) suggested that male rats that were exposed to acetaminophen on PND 10 altered spontaneous behavior and habituation patterns in male rats. Some studies showed that PND10 corresponds to the time around birth in humans in key developmental processes. Many studies showed comorbidities associated with postnatal acetaminophen were estimated to be about $40 \%$ of the risk of ASD among male children in the US (Philippot, et al., 2021).

In fact, the current work tried to evaluate the effect of acetaminophen on the behavioral test responses to postnatal exposure to acetaminophen in rats which are still not well understood. Multiple human and animal studies suggested that prenatal and postnatal acetaminophen use is associated with abnormal offspring neurodevelopment. The mechanism may involve disrupted endocrine function, which has been shown in animal studies to affect fetal brain development. Another possibility is that acetaminophen disrupts brain development through dysregulation of oxidative stress (Tovo-Rodrigues, $\boldsymbol{e t}$ al., 2018).

In this work Nest Seeking Test (olfactory discrimination) was performed for all pups at PND 9 (Zou, et al., 2015). Pups of the control group were approached maternal bedding significantly higher than those of the acetaminophen group (impaired in nest seeking responses). These observations are in accordance with those of Saeedan et al., in 2018, who suggested that impaired in nest seeking responses in pups that were exposed to acetaminophen postnatally may be due to acetaminophen alters neural circuits in brain regions that are implicated in ASD, such as the amygdala a collection of cells near the base of the brain (Saeedan, et al., 2018). There are two, one in each hemisphere or side of the brain. The amygdala undergoes significant functional, morphological, and physiological maturation during the first two weeks of pups' development. Insult and disruption of these circuits during this period can dramatically alter socioemotional behavior and lead to behavioral 


\section{Ghada A. Taqa et al......}

abnormalities and impaired to recognize the nest (Barrett, et al., 2017).

Amygdala abnormalities in the structure and neuronal density during social tasks have been reported in patients with ASD (Ko et al., 2015). Similar results were reported by Klein et al. in 2020, who suggest that the evaluation of sensory functions indicated impaired olfactory discrimination. In general, impairment of nest-seeking behavior may be caused by: 1) motor deficit; 2) reduction of social interest by the smell of mother and siblings or 3) decreased perception and processing of any olfactory stimuli (Klein, et al., 2020).

The second behavioral test was NG. It is the upward migration of rats on an inclined plane. As a result, NG is acting as a major behavioral tool for evaluating neurodevelopmental illnesses, potentially useful even at a young age when other behavioral tests are unavailable. As a result, the goal of our research was to assess the role of $\mathrm{NG}$ as an early behavioral diagnostic of autism (Lefter, et al., 2020). It is an automatic unlearned response and directional movement against gravitational signals that aid in the study of sensory or proprioceptive function as well as the evaluation of motor development (reflexes) activity, visuospatial development and vestibular activity (Liu, et al., 2015)

In our study, there is a significant increase in the rotation time 180 degrees among the pups of the acetaminophen group compared to those of control and melatonin-treated groups. These findings were similar to Ghanem et al., in 2016 who confirmed that acetaminophen has direct neurotoxic effects on rat brain neurons in vitro and in vivo through his work and also suggested this toxic effect may be due to acetaminophen metabolism by the cytochrome P-450 CYP2E1 isoform which generates a highly reactive metabolite N-Acetyl-P Benzoquinoneimine. This highly reactive compound is conjugated with GSH, producing a decrease in glutathione levels in neurons that leads to neuronal death (Ghanem, et al., 2016).

In the early behavioral investigation, $\mathrm{NG}$ is important as a controller of vestibular functions in the developmental sequence after sensory function starts. This is an innate postural response that enhances in the early age of rats. Actually, NG has been validated in many neurological and neurodevelopmental conditions such as decline recurrent seizure in neonates, infantile spasm, ASD, and others (Ni, et al., 2015). The geotaxis development in the acetaminophen rat model of ASD with more data collected over time. It was used in the ASD animal model to examine mesocortical dopaminergic activity. The mesocortex structurally transitional between the neocortex and the allocortex includes the cingulate gyrus, fasicolar gyrus, and isthmus. The allocortex and mesocortex incorporate the limbic lobe, an artificial construct formed from parts of other lobes and located on the medial aspect of the hemisphere, where it forms a ring around the corpus callosum and rostral brainstem (Wang, et al., 2021).

Another study by Blecharz-Klin et al., (2016) demonstrated that postnatal acetaminophen exposure to rats results in changes in the level of catabolic endproducts of serotonin (5-HIAA) and noradrenaline (MHPG) degradation because of acetaminophen on monoaminergic neurotransmission in the cerebellum. Since the cerebellum has an important role in motor control, any cerebellum dysfunction often presents with motor signs. It is active in coordination, precision, and timing of movements and motor learning. This may be the reason why acetaminophen increase in time taken to rotate 180 degrees. While Saeedan et al., (2018) suggested that the reduction of the Purkinje cell in the cerebellum was observed in rats exposed to acetaminophen may adversely affect the normal functions of the cerebellum and lead to a significant reduction in performance on NG test by rats exposed postnatally to acetaminophen. Jaswal et al., (2019) suggested there has been no evidence reported to date indicating that acetaminophen alters attentional processes such as those associated with visual target identification, for example, processes impacted by offtask attentional states that precede more evaluative stages of analyses in the afferent stream of visual stimulus processing.

Regarding the melatonin-treated group, there is a significant difference in values between pups exposed to acetaminophen alone and pups of the melatonintreated group in time taken to rotate 180 degrees. This study showed improvement in values of the melatonintreated group during NG performance. These findings are in accordance with Bazrgar, et al., (2015) who observed that exposed to lead $(\mathrm{Pb})$ may impair the motor activities of rats and suggested that melatonin treatment can improve motor deficits and oxidative stress protecting the cerebellum against $\mathrm{Pb}$ toxicity. Furthermore, Motallebzadeh, et al., (2020) suggest that melatonin showed a capacity for neuroprotective activity in treating irradiation-induced oxidative stress and apoptosis in the brainstem of rats; however, the use of melatonin as a neuroprotective agent in humans requires further study, particularly clinical trials.

In this work, Open-Field Test was performed to assess the locomotors activity and anxiety-like behaviuor in pups of control, acetaminophen and melatonin-treated groups. Our observation indicated 


\section{Effects of Melatonin on Behavioural Activities in......}

features of alteration in locomotors activity (hyperactivity) during the open-field test as the total distance was greater in rats exposed to acetaminophen compared to those of control and melatonin-treated rats.

These findings are consistent with those of other researchers (Mony, et al., 2016). The explanation of this feature may be due to many reasons. At the beginning and according to the anatomy of central motor structures which including the motor cortex, cerebellum, basal ganglia, and spinal cord, BrainDerived Neurotrophic Factor exerts both neurotrophic and direct electrophysiological effects via a highaffinity tyrosine receptor kinase $\mathrm{B}$ receptor and a common low-affinity p75 neurotrophin- receptor (Ueda, et al., 2020). The loss of BDNF usually leads to neurodegeneration in these motor centers and eventually results in several severe motor diseases such as vestibular syndrome (Mandel, et al., 2009).

Many studies confirmed that compounds that act on cannabinoid systems such as acetaminophen lead to alteration BDNF level in the brain region; this may explain the alteration in motor activity that occurred in the acetaminophen group. Our findings are in accordance with those of other (Stergiakouli, et al., 2016). In addition, some studies observed significant alteration on various neurotransmitters (e.g., serotonergic, noradrenergic, dopaminergic and neurotrophic) following developmental exposure to acetaminophen, which leads to alteration motor activity (Essawy, et al., 2017).

On the other hand, the values of the open field test showed that the rats exposed to acetaminophen alone traveled to the central zone less than those in the control and melatonin-treated groups. These results demonstrate that anxiety levels in acetaminophen groups are significantly higher than control and melatonin-treated groups. Brain regions such as the amygdala, hippocampus and cortex, directly involved in the regulation of emotional behaviour, contain high densities of $\mathrm{CB} 1$ receptors, which are responsible for the analgesic effect of acetaminophen and responsible for the anxiogenic effect of acetaminophen (Wang, $\boldsymbol{e t}$ al., 2020). Chen et al. (2018) suggested that acetaminophen increases anxiety-like behaviour and impairs recognition memory in mice. It was mediated by the activation of the endocannabinoid system, as a cannabinoid type-1 receptor antagonist reversed it compared to controls.

This study showed an improvement in the parameters of open field test after melatonin administration; these findings are similar to Genario, et al., (2020) who reported in an animal study that melatonin increased levels of gamma-aminobutyric acid (GABA) in certain parts of the brain. Higher GABA levels can have a calming effect and reduce anxiety symptoms (Genario, et al., 2020).

\section{CONCLUSION}

The exposure of pups to acetaminophen induces behavioral alterations such as delay to approach the maternal bedding, increase in time taken to turn 180 degrees, an increase in locomotors activity, lowering in the functional memory outcomes, have a higher percentage of side-preference rates, and disruption in the social behavior compared to control and melatonin treated groups. All these alterations indicating precipitate of autistic-like behaviour, were reduced by giving melatonin.

\section{Declaration of Conflicting Interests}

The authors revealed that there was no potential conflicts of interest.

\section{REFERENCES}

Al-ALLAF L. K., and Al-ASHOO H. A., 2021. The effect of CO-Q10 on the testicular histological changes in rats induced by imatinib. Iraqi Journal of Veterinary Sciences, 35(1), 189-196.

DOI:http://dx.doi.org/10.33899/ijvs.2020.126587.1347.

AI-JUREISY, I., AI-WATTAR W .T., and TAQA A, G., 2020. Evaluation of The Analgesic Activity of Coenzyme Q10 Ointment in Mice. Journal of Applied Veterinary Sciences, 5(1), 11-16.

DOI:https://dx.doi.org/10.21608/javs.2019.20868.1001

ALI Z., and BHASKAR S. B., 2016. Basic statistical tools in research and data analysis. Indian journal of anesthesia, 60(9) 662.

DOI:https://dx.doi.org/10.4103\%2F0019-5049.190623

ASYMIDA. F., DIMYATI Y., LUBIS B., LELO A., ALI M., PASARIbU A. P., and PASARIBU S., 2020. Intravenous and Oral Paracetamol Have the Same Effect in Reducing Fever in Pediatric Patients. Molecular and Cellular Biomedical Sciences,4(3), 140145.DOI:http://dx.doi.org/10.21705/mcbs.v4i3.147.

BAKER S., and SHAW W., 2021. Autism, Fungal Infection, MycoTOX Resources, Mycotoxins, MycoToxins Case study: Rapid Complete Recovery From An Autism Spectrum Disorder After Treatment of Aspergillus With The Antifungal Drugs Itraconazole And Sporanox. Autism, 19(4), 20-27. PMID: 33132781; PMCID: PMC7572136. https://www.greatplainslaboratory.com

BARRETT C. E., HENNESSEY T. M., GORDON K. M., RYAN S. J., MCNAIRM L., RESSLER K. J., and RAINNIE D. G., 2017. Developmental disruption of amygdala transcriptome and socioemotional behavior in rats exposed to valproic acid prenatally. Molecular autism, 8(1), 42. https://doi.org/10.1186/s13229-0170160-X.

BAZRGAR M., GOUDARZI I., LASHKARBOLOUKI T., and SALMANI M. E., 2015. Melatonin ameliorates oxidative damage induced by maternal lead 
exposure in rat pups. Physiology and behavior, 151, 178-188.

https://doi.org/10.1016/j.physbeh.2015.06.040.

BITTKER, S. 2016. Antioxidant sulfur compounds: Potential therapies for autism. Journal of Autism, 3,15.DOI: 10.7243/2054-992X-3-3.

BJORKLUND G., MEGUID N. A., El-BANA M. A., TINKOVA. A., SAAD K., DADAR M., and CHIRUMBOLO S., 2020. Oxidative stress in autism spectrum disorder. Molecular neurobiology, 57(5), 2314-2332. https://doi.org/10.1007/s12035-019-01742-2.

BLECHARZI-KLINI, K., JONNIEC-MACIEJAK I., JAWNA-BOINSKA K., PYRZANOWSKA J., PIECHAL A., WAWER A., and WIDYTYSZKIEWICZ E., 2016. Cerebellar level of neurotransmitters in rats exposed to paracetamol during development, Pharmacological Reports. 68(6), 11591164. https://doi.org/10.1016/j.pharep.2016.06.005

CHEN, Z., WEI H., PERTOVAARA A., WANG J., and CARLSON S., 2018. Anxiety and activity related effects of paracetamol on healthy and neuropathic rats. Pharmacology research and perspectives, 6(1), e00367. https://doi.org/10.1002/prp2.367.

DAWOOD, G. A., TAQA, A G., and ALNEMA, M. M., 2020. Histological Effect Of Coq10 On Liver And Buccal Mucosa In Mice. Journal of Applied Veterinary Sciences, 5(2),1-

5.https://dx.doi.org/10.21608/javs.2020.85543.

El-ANSARY A., Al-GHAMDI M., BHAT R. S., AlDAIHA N. S., and Al-AYADHI L., 2016. Potency of pre-post treatment of coenzyme Q10 and melatonin supplement in ameliorating the impaired fatty acid profile in rodent model of autism. Food and Nutrition Research, $60(1)$ https://doi.org/10.3402/fnr.v60.28127

ELLENBROEK B., and YOUN J., 2016. Rodent models in neuroscience research: is it a rat race? Disease models and mechanisms, 9(10), 1079-1087. https://doi.org/10.1242/dmm.026120.

ESSAWY A. E., ALKHURIJI A. F., and SOFFAR A. A., 2017. Paracetamol overdose induces physiological and pathological aberrations in rat brain. Journal of Applied Pharmaceutical Science. 7(09): 185-190. http://dx.doi.org/10.7324/JAPS.2017.70925.

GENARIO R., GIACOMINI A. C., DE ABREU M. S., MARCON L., DEMIN K. A., and KALUEFF A. V., 2020. Sex differences in adult zebrafish anxiolytic-like responses to diazepam and melatonin. Neuroscience letters, 714, 134548. https://doi.org/10.1016/j.neulet.2019.134548.

GHANEM C. I., PEREZ M. J., MANAUTOU J. E., and MOTTINO A. D., 2016. Acetaminophen from liver to brain: new insights into drug pharmacological action and toxicity. Pharmacological research, 109, 119-131. . https://doi.org/10.1186/s13229-017-0160-X.

JASWAL S. M., GRANADOS SAMAYOA, J. A., KAM, J. W., RANDLES, D., HEINE, S. J., and HANDY, T. C., 2019. The influence of acetaminophen on task related attention. Frontiers in neuroscience. 13: 444. https://doi.org/10.3389/fnins.2019.00444.

KLEIN R. M., RIGOBELLO C., VIDIGAL C. B., MOURA K. F., BARBOSA D. S., GERARDIN D. C. C., and MOREIRA E. G., 2020. Gestational exposure to paracetamol in rats induces neurofunctional alterations in the progeny. Neurotoxicology and teratology, 77,106838 .

http://dx.doi.org/10.1016/j.ntt.2019.106838.

KO C. H., HSIEH T. J., WANG P. W., LIN W. C., YEN C. F., CHEN C. S., and YEN J. Y., 2015. Altered gray matter density and disrupted functional connectivity of the amygdala in adults with Internet gaming disorder. Progress in NeuroPsychopharmacology and Biological Psychiatry, 57, 185-192. https://doi.org/10.1016/j.pnpbp.2014.11.003.

KUBATKA P., ZUBOR P., BUSSELBERG D., KWON T. K., ADAMEK M., PETROVI C. D., and KRUZLIAK P., 2018. Melatonin and breast cancer: Evidences from preclinical and human studies. Critical reviews in oncology/hematology, 122, 133-143. https://doi.org/10.1016/j.critrevonc.2017.12.018.

LALANNE S., FOUGEROU -LEURENT C., AADERSON G. M., SCHRODER C. M., NIR T., CHOKRON S., and TORDJMAN S., 2021. Melatonin: From Pharmacokinetics to Clinical Use in Autism Spectrum Disorder. International Journal of Molecular Sciences, 22(3).

http://dx.doi.org/10.3390/ijms22031490.

LEEFTER R., CIOBICO A., ANTIOCH I., ABABIE D. C., HRITCU L., and LUCA A. C., 2020. Oxytocin Differentiated Effects According to the Administration Route in a Prenatal Valproic Acid-Induced Rat Model of Autism. Medicina, 56(6), 267. https://doi.org/10.3390/medicina56060267.

LIU H., HAN M., LI, Q., ZHANG X., WANG W. A., and HUANG F. D., 2015. Automated rapid iterative negative geotaxis assay and its use in a genetic screen for modifiers of $A \beta$ 42-induced locomotor decline in Drosophila. Neuroscience bulletin, 31(5), 541-549. https://doi.org/10.1007/s12264-014-1526-0.

MANDEL A. L., OZDENER H., and UTERMOHLEN V., 2009. Identification of pro-and mature brainderived neurotrophic factor in human saliva. Archives of oral biology, 54(7), 689-695. https://doi.org/10.1016/j.archoralbio.2009.04.005.

MONY T. J., LEE, J. W., DREYFUS C., DICICCOBLOOM, E., and LEE H. J., 2016. Valproic acid exposure during early postnatal gliogenesis leads to autistic-like behaviors in rats. Clinical Psychopharmacology and Neuroscience, 14(4), 338. https://doi.org/10.9758/cpn.2016.14.4.338.

MOTALLEBZADEH E., TAMEH A. A., ZAVAREH S. A. T., FARHOOOD B., ALIASGHARZEDEH A., and MOHSENI M., 2020. Neuroprotective effect of melatonin on radiation-induced oxidative stress and apoptosis in the brainstem of rats. Journal of cellular physiology, 235(11), 8791-8798.

DOI:https://doi.org/10.1002/jcp.29722.

NAIR A. B., and JACOB S., 2016. A simple practice guide for dose conversion between animals and human. Journal of basic and clinical pharmacy, 7(2), 27. https://doi.org/10.4103/0976-0105.177703.

NI H., SUN Q., TIAN T., FENG X., and SUN B. L., 2015. Prophylactic treatment with melatonin before recurrent neonatal seizures: Effects on long-term neurobehavioral changes and the underlying expression of metabolismrelated genes in rat hippocampus and cerebral cortex. 
Pharmacology Biochemistry and Behavior, 133,25-30. https://doi.org/10.1016/j.pbb.2015.03.012.

PARKER W., HORNIK C. D., BILBO S., HOLZKNECHT Z. E., GENTRY L., RAO R., and NEVISON C. D., 2017. The role of oxidative stress, inflammation and acetaminophen exposure from birth to early childhood in the induction of autism. Journal of International Medical Research, 45(2), 407-438. https://doi.org/10.1177/0300060517693423.

PELSOCZI P., KELEMEN K., CSOLLEC., NAGY G., LENDVAI B., ROMAN V., and LEVAY G., 2020. Disrupted Social Hierarchy in Prenatally ValproateExposed Autistic-Like Rats. Frontiers in behavioral neuroscience, 13, 295.

https://doi.org/10.3389/fnbeh.2019.00295.

PHILIPPOT G., GORDH T., FREDRIKSSON A., and VIBERG H., 2017. Adult neurobehavioral alterations in male and female mice following developmental exposure to paracetamol (acetaminophen): characterization of a critical period. Journal of Applied $\begin{array}{llll}\text { Toxicology, } & 37(10) . & 1174 & -1181\end{array}$ http://dx.doi.org/10.1002/jat.3473.

PHILIPPOT G., HELLSTEN S. V., VIBERG H., and FREDRIKSSON R., 2021. Evaluation of the dentate gyrus in adult mice exposed to acetaminophen (paracetamol) on postnatal day 10. International Journal of Developmental Neuroscience, 81(1), 91-97.DOI: 10.1002/jdn.10079.

https://onlinelibrary.wiley.com/doi/abs/10.1002/jdn.10079.

PIRES L. R., GUARINO V., OLIVEIRA M. J., RIBEIRO C. C., BARBOSA M. A., AMBROSIO L., and PEGO A. P., 2016. Ibuprofen-loaded poly (trimethylene carbonate-co- $\varepsilon$-caprolactone) electrospun fibres for nerve regeneration. Journal of tissue engineering and regenerative medicine, 10(3), 154-166. https://doi.org/10.1002/term.1792.

RIGOBELLO C., KLEIN R. M., DEBIASI J. D., URSINI L. G., MICHELIN A. P., MATSUMOTO A. K., and MOREIR E. G., 2021. perinatal exposure to paracetamol: dose and sex-dependent effects in behavior and brain's oxidative stress markers in progeny. Behavioural Brain Research, 408, 113294. https://doi.org/10.1016/j.bbr.2021.113294.

RUHELA R. K., SONI S., SARMA P., PRAKASH A., and MEDHI B., 2019. Negative geotaxis: An early age behavioral hallmark to VPA rat model of autism. Annals of Neurosciences, 26(1), 25-31. https://doi.org/10.5214/ans.0972.7531.260106.

SAEEDAN A. S., SINGH I., ANSARI M. N., Singh, M., RAWAT J. K., DEVI U., and KAITHWAS G., 2018. Effect of early natal supplementation of paracetamol on attenuation of exotoxin/endotoxin induced pyrexia and precipitation of autistic like features in albino rats, Inflammopharmacology. 26(4), 951-961. https://doi.org/10.1007/s10787-017-0440-2.

SZTAINBERG Y., and ZOGHBI H. Y., 2016. Lessons learned from studying :syndromic autism spectrum disorders. Nature neuroscience, 19(11), 1408. https://doi.org/10.1038/nn.4420

TAQA, G. A. 2013. Evaluation of antidepressant activity of diphenhydramine in mice. Innovare Journal of Medical Science, 1(2), 15-18. https://innovareacademics.in/journals/index.php/ijms/article/v iew/338

TEMPLE A. R., ZIMMERMAN B., GELLOTTE C., and KUFFNER E. K., 2017. Comparison of the Efficacy and Safety of 2 Acetaminophen Dosing Regimens in Febrile Infants and Children: A Report on 3 Legacy Studies. The Journal of Pediatric Pharmacology and Therapeutics, 22(1), 22-32. https://doi.org/10.5863/1551-6776-22.1.22.

TOVO-RODRIGUES L., SCHNEIDER B. C., MARTINS -SILVA T., DEL-PONTE B., DE MOLA C. L., SCHULER -FACCINI L., and BERTOLDI A. D., 2018. Is intrauterine exposure to acetaminophen associated with emotional and hyperactivity problems during childhood? Findings from the 2004 Pelotas birth cohort. Biomedcentral Psychiatry.18(1), 1-11. http://doi.org/10.1186/s12888018-1942-1.

UEDA I., TAKEMOTO K., WATANABE K., SUGIMOTO K., IKEN OUCHI A., KAKEDA S., and KORGI Y., 2020. The brain-derived neurotrophic factor Val66Met polymorphism increases segregation of structural correlation networks in healthy adult brains. Peer Journal, 8, e9632. https://doi.org/10.7717/peerj.9632.

VIBERG H., ERIKSSON P., GORDH T., and FREDRIKSSON A., 2014. Paracetamol (acetaminophen) administration during neonatal brain development affects cognitive function and alters its analgesic and anxiolytic response in adult male mice. toxicological sciences, 138(1), 139-147. https://doi.org/10.1093/toxsci/kft329.

WANG Q., WEI S., I, H., ZHANG M., WANG P., ZHU Y., and BAI X., 2021. Neuroanatomical and functional substrates of the greed personality trait. Brain Structure and Function, 226(4):1269-1280. doi:10.1007/s00429021-02240-9.

WANG Z., ALDERMAN M. H., ASGARI C., and TAYLOR H. S., 2020. Fetal Bisphenol-A Induced Changes in Murine Behavior and Brain Gene Expression Persisted in Adult-aged Offspring. Endocrinology, 161(12), baqaa 164. https://doi.org/10.1210/endocr/bqaa164.

ZOU J., WANG W., PAN Y. W., LU S., and XIA Z., 2015. Methods to measure olfactory behavior in mice. Current protocols in toxicology, 63(1), 11-18. https://doi.org/10.1002/0471140856.tx1118s63

How to cite this article:

Ghada, A. Taqa; Hiba, A. Al-Sheikh; and Luma, I. Al-Allaf, 2021. Effects of Melatonin on Behavioural Activities in Acetaminophen-Induced Autism in Rat. Journal of Applied Veterinary Sciences, 6 (4): $58-66$.

DOI:https://dx.doi.org/10.21608/javs.2021.89536.1098 